\title{
Structure and Microscopic Wear Analysis of Lining Material Based on EDEM
}

\author{
Zhongsheng Wang ${ }^{1, a}$, Rujie Wang ${ }^{1, b}$, Qiou Fei ${ }^{1, c}$, Jianguo Li ${ }^{2, d}$, Jiachen Tang ${ }^{2, e}$ and Boqiang Shi', \\ ${ }^{1}$ Anshan Iron and Steel Group Mining Co., Ltd. equipment manufacturing branch, China \\ ${ }^{2}$ School of Mechanical Engineering, University of Science and Technology Beijing, China
}

\begin{abstract}
The microscopic influence of sliding distance and load on the wear of cone crusher liner is studied. The main factors that affect the hardness of the liner and the material are clearly put forward, and the hardness of the liner is verified according to the national standard to ensure the correctness of the lining and the ore material. Simulation experiments were carried out with EDEM. When the material was certain, the positive pressure and sliding distance between the ore and liner were changed, and the micro wear of the liner was quantitatively calculated by the number of bond keys of the lining plate. The results show that when the liner moves at the same distance, the pressure is greater and the lining plate is seriously worn. When the lining plate is subjected to the same pressure, the moving distance increases, and the lining plate is seriously worn. This method has some reference value for cavity design of new crusher and other material wear
\end{abstract}

\section{Introduction}

When the cone crusher breaks the ore, the movable cone liner is worn by the squeezing action of the ore, so the movable cone liner needs to be replaced regularly. For large crushing equipment, replacing the lining of the frequency, crushing efficiency and, business efficiency is closely related. Therefore, the research on the wear of the movable cone liner is very important. It has been found that the wear of the movable cone liner depends on the wear properties of the liner material and, on the other hand, the mechanical action, such as the sliding distance between the movable cone liner, the ore and, the load of the movable cone liner ${ }^{[1]}$. In this paper, the effect of different sliding distance and load on the wear of the movable cone liner under the dry friction condition is studied by using the discrete element method to study the effect of the composite material and the crushing cavity type Provide reference.

\section{Cone liner material and ore material structure}

In order to study the wear of the movable cone liner, it is necessary to construct the dynamic cone liner material and the ore material. The material of the liner is set according to the microscopic parameters (shear modulus, Poisson's ratio, particle radius, particle stiffness, bonding bond strength, etc.) of the actual material, which makes the material model consistent with the mechanical properties of the material. The main component of the material is $\mathrm{ZGMn} 13 \mathrm{Cr} 2$, the main component of the ore material is limestone, assuming that the material particles are uniform, the main parameters of the lining material and the ore material are shown in Table 1:

Table 1 Basic parameters of liner material and ore material

\begin{tabular}{c|c|c|c|c}
\hline & Poisson's ratio & $\begin{array}{c}\text { Elastic } \\
\text { modulus } \\
(\mathrm{GPa})\end{array}$ & $\begin{array}{c}\text { Compre } \\
\text { ssive } \\
\text { strength } \\
\text { (Mpa) }\end{array}$ & $\begin{array}{c}\text { Particle } \\
\text { radius } \\
(\mathrm{mm})\end{array}$ \\
\hline Liner & 0.26 & 200 & 1500 & 1 \\
\hline ore & 0.3 & 41 & 140 & 1 \\
\hline
\end{tabular}

In the EDEM Hertz-mindlin with bonding contact model, the normal stress and tangential stress limits between the particles are:

$$
\begin{gathered}
\sigma_{\max }<-\frac{F_{n}}{A}+\frac{2 M_{t}}{J} R_{b} \\
\tau_{\max }<-\frac{F_{t}}{A}+\frac{M_{n}}{J} R_{b}
\end{gathered}
$$

$F_{n}$ is the normal force between particles; $F_{t}$ is the

\footnotetext{
a1993962830@qq.com, bas_wangrujie@sina.com, ${ }^{c} 8815587 @ q q . c o m,{ }^{d}$ guo-email@163.com, ${ }^{\mathrm{e}} 1357273236 @ q q . c o m$, fustb1007@163.com
} 
tangential force between particles; $M_{n}$ is the normal moment between particles; $R_{b}$ is the intergranular bonding radius. $A=\pi R_{b}^{2}, J=\pi R_{b}^{4}$, The normal compressive strength of the material $\sigma_{\max }$ can be found by the data.

In the EDEM model, because the particle size is mostly macroscopic state, the cohesive force between the particles is often neglected to influence the tangential force ${ }^{[2]}$. From the formula (1) and (2), it can be seen that the hardness and the normal stiffness of the material $k_{n}$, the tangential stiffness $k_{t}$ are related to the bonding radius after the particles are completely bonded.

$k_{n}=\frac{\sqrt{2 r} E}{3\left(1-\mu^{2}\right)}=\frac{\sqrt{2 \times 0.001} \times 2 \times 10^{11}}{3\left(1-0.26^{2}\right)}=1.01 \times 10^{9}$

Since the calculation of $k_{t}$ is very complex, according to Mindlin ${ }^{[3]}$ analysis results, the elastic entity in the event of contact, the oval contact area ratio $k_{t} / k_{n}=[2 / 3,1]$, here take

$k_{t}=\frac{2}{3} k_{n}=0.673 \times 10^{9}$

The maximum compressive strength of ZGMn13Cr2 can reach $1500 \mathrm{MPa}$, cohesion can be ignored, particle radius is $0.1 \mathrm{~mm}$, the bonding radius is $0.15 \mathrm{~mm}$. After the material is constructed, it is necessary to measure the hardness of the material. According to the national standard GB / T230.1-2004 ${ }^{[4]}$, Rockwell hardness in the range of $20 \mathrm{HRB} \sim 100 \mathrm{HRB}$, the pressure head with a diameter of $1.5875 \mathrm{~mm}$ carbide ball. The main test force $F_{0}=98.07 \mathrm{~N}$, the main test force $F_{1}=882.6 \mathrm{~N}$, the total force $F=980.67 N$ points in two steps into the sample surface, after a specified time, the removal of the main test force, measured at the initial test force Of the residual indentation depth $h$, the Rockwell hardness is $\mathrm{H}$ :

$$
\mathrm{H}=130-\frac{h}{0.002}
$$

To measure the depth of the indenter material, the ram was applied at a rate of $0.1 \mathrm{~m} / \mathrm{s}$. The pressure of the indenter changes with time as shown in Fig.1.The least squares method is used to fit a 4 -step ${ }^{[5]}$ smooth curve.

$\mathrm{F}=1.5943 \times 10^{14} \mathrm{t}^{4}-4.4013 \times 10^{13} \mathrm{t}^{3}+4.4560 \times$
$10^{12} \mathrm{t}^{2}-2.0959 \times 10^{11} \mathrm{t}+3.6153 \times 10^{9}$

Formula (4) is the relationship between the force of the indenter $\mathrm{F}$ and the time $\mathrm{t}$. According to the experience of material rebound ${ }^{[6]}$, We can measure indentation $h=(0.07047-0.06829) \times 100 \times 0.85=0.1853 \mathrm{~mm}$ , According to equation (3), the Rockwell hardness is 37.35 .

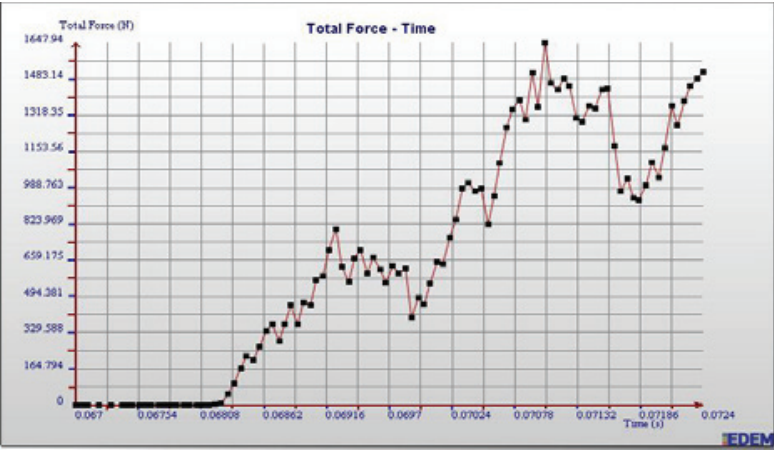

Fig.1 The pressure of the indenter changes with time

In order to verify the correctness of the liner hardness measurement, by measuring the liner strength, according to the national standard GB / T1172-1999 steel strength and hardness of the conversion value, you can indirectly get hardness.

The particles having a radius of $0.05 \mathrm{~mm}$ were bonded into $4 \mathrm{~mm} \times 1 \mathrm{~mm} \times 0.7 \mathrm{~mm}$ blocks with the same bonding parameters as measured in Fig. 1, the left half of the block was fixed in the housing and the other end was extended into the housing. From the middle of the block $1.5 \mathrm{~mm}$, with a pressure plate at a constant rate of pressure to the block, as shown in Fig.2. The strength of the material can be obtained by force in the vertical direction by the platen. Fig. 3 shows that the pressure plate at $62.8304 \mathrm{~N}$, the block broken, according to formula (6), the block of the tensile strength is $1154 \mathrm{Mpa}$.We can see that the hardness of the material is 36 . And the direct hardness measured by the error:

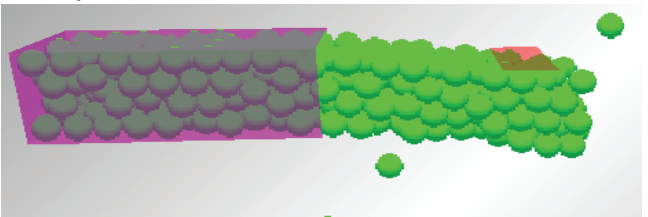

(a)

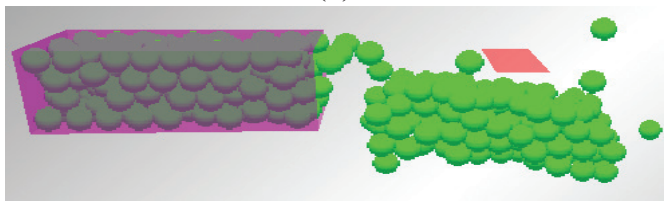

(b)

Fig. 2 Strength measurement model 


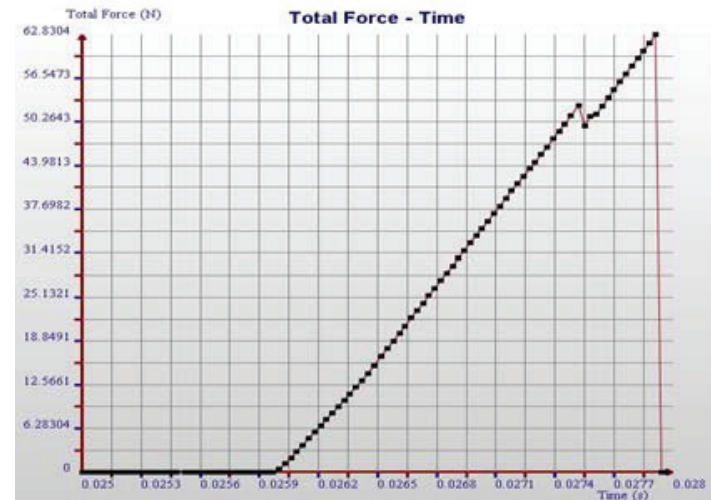

Fig. 3 Pressure plate with time variation

We change the value of $k_{t} 、 k_{n}$ in equal proportion, we can get different hardness of the material, through the simulation experiment can be obtained between the hardness and stiffness of the material. When other factors remain unchanged, $k_{t} 、 k_{n}$ in a certain range increases, the hardness first increased and then reduced. When too large or too small, the particles will not bond. By selecting different parameters, you can construct different hardness of the material. Similarly, the same method used to construct limestone materials.

\section{Study on the Factors Affecting Wear of Conical Liner}

For the liner wear, domestic and foreign scholars have carried out experimental research, and the establishment of the corresponding wear model, given some wear calculation formula ${ }^{[7]}$.Archard in the study of gear meshing sliding, considering the contact stress, sliding speed, plastic deformation contact area and other factors, put forward the classic wear equation ${ }^{[8-9]}$, and is widely cited so far, the wear calculation formula:

$$
\omega=K s \frac{P}{P_{m}}
$$

$\omega$ is the wear loss; $S$ is the slip distance ; $P$ is contact surface load; $P_{m}$ is the softer material hardness; $K$ is wear coefficient.

We can derive from equation (5) that wear is related to wear coefficient, load, slip distance and material hardness. Because the wear coefficient and the hardness of the material are related to the degree of lubrication and the material itself, the positive pressure and the sliding distance between the ore and the liner are changed when the material is constant. The liner wear simulation process is shown in Fig. 4.

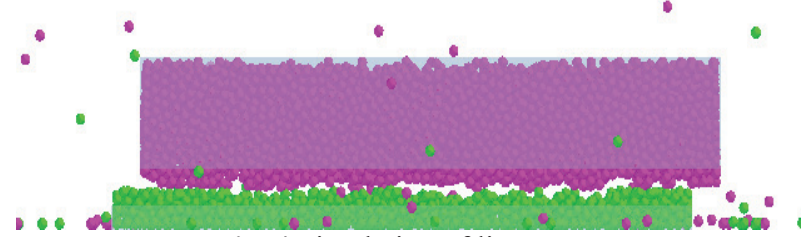

Fig. 4 Simulation of liner wear
In Fig. 4, the upper material is limestone, the lower material is the liner, the ore material is long, wide and high, respectively $12 \mathrm{~mm}, 1 \mathrm{~mm}, 2 \mathrm{~mm}$, the movement displacement is $1 \mathrm{~mm}$. Since EDEM can not directly set the positive pressure between the ore and the liner, through the fixed liner, change the vertical movement speed of the ore, so that the pressure between the two changes. Figure 6 shows the vertical velocity of the ore $v$ $=0.001 \mathrm{~m} / \mathrm{s}$, frequency f were $40 \mathrm{HZ}, 60 \mathrm{HZ}, 80 \mathrm{HZ}$ liner bond bond breaking number.

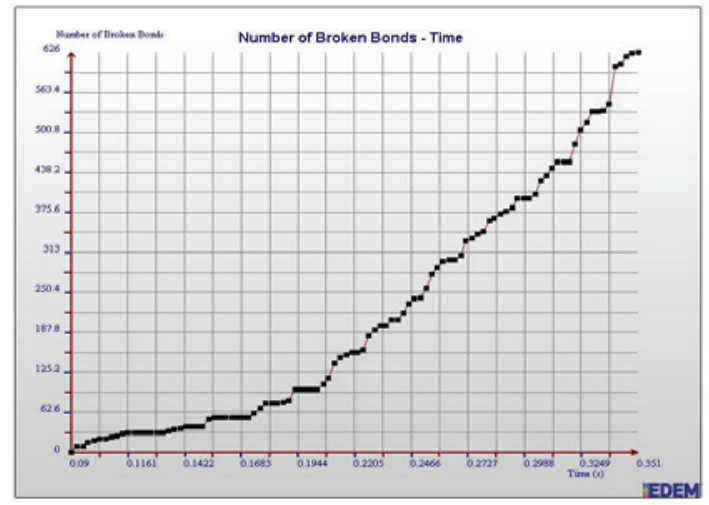

(a) The amount of liner material wear when $\mathrm{f}=40 \mathrm{HZ}$

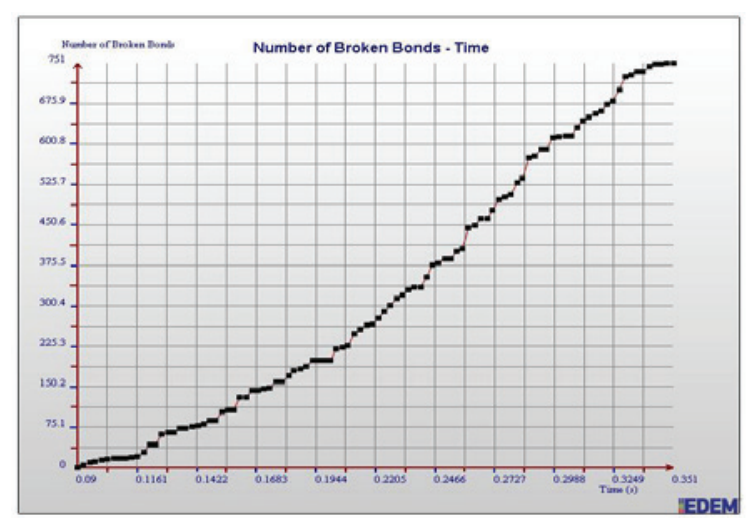

(b) The amount of liner material wear when $\mathrm{f}=60 \mathrm{HZ}$

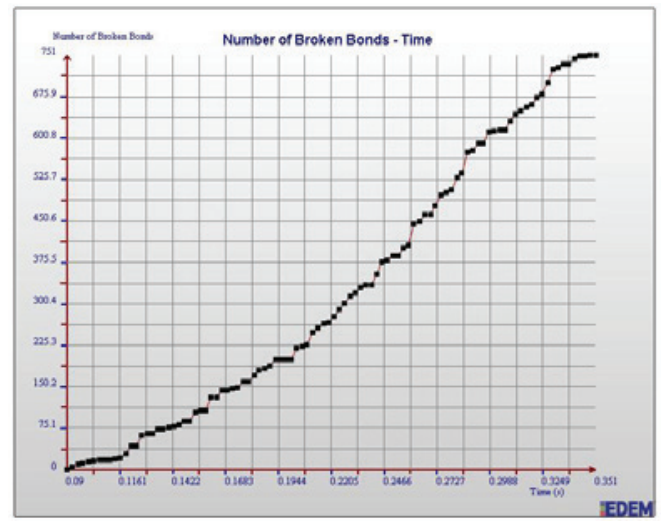

(c) The amount of liner material wear when $\mathrm{f}=80 \mathrm{HZ}$

Fig. 5 different ore movement frequency under the liner material wear 
The following conclusions can be drawn from Fig. 5:

(1) For the same frequency, as time increases, that is, the movement distance increases, the liner bond bond number increases, that is, liner wear increases;

(2) For different frequencies, take a certain moment, the frequency of the liner bond bond number broken, that is, high frequency, the same time the distance of movement, liner wear serious.

\section{Conclusions}

This paper mainly studies the influence of ore slipping distance and load on liner wear. First study the factors that affect the hardness of the cone material and the ore material, and then construct the dynamic cone liner and ore material. According to the national standard to verify the hardness of the material to ensure the correctness of the material structure. Secondly, the effects of different materials on the wear and tear of the cone are studied. The method reduces the physical test and saves the material cost. Plate material selection and research has important reference value.

\section{References}

1. Chao Wang, Yahui Hu, Yanqing Tan, etc.2014.Study on wear rate prediction model of sliding guideway based on Archard wear theory [J], Lubrication and Sealing, 39 (8): 73-76.

2. Qiang Lei. 2011. Research on material breakage mechanism based on discrete element [D]. Jiangxi University of Technology.

3. Mindlin R D. Compliance of elastic bodies in contact. 1949.Journal of Applied Mechanics, 16: 259-268.

4. China Institute of Metrology Science. 1999.GB/T 1172-1999 hardness and strength conversion value of ferrous metals [S]. Beijing: China Standard Press, 2.

5. Hui Ni. 2010. Research on some problems in the fitting of moving least squares data [D]. Hangzhou: Zhejiang University of Technology.

6. Lin Jingyu. 2015. Evaluation of Uncertainty of Metal Rockwell Hardness Measurement [j], Technology and Enterprise, 09:176-177.

7. Guobin Li,Delin Guan,Mingxing Zhang. 2008. Study on friction and wear behavior of surface nanometer carbon steel in dry friction condition [J], Journal of Tribology, 28 (1): 39-43.

8. Changlin Gui. 1990. Archard wear design calculation model and its application method [J], Lubrication and Sealing,(1): 12-21.

9. Challen J M, Oxley P L. 1986.Prediction of Archard wear coefficient for metallic sliding friction assuming a low cycle fatigue wear mechanism [J]. Wear, (111): 275-288. 